at the time of making a comparison, seems to have no appreciable effect on the color. There is always more or less reduction of the chromic acid, if it comes into contact with even very small particles of dust or dirt, so that the safest procedure is to use only freshly prepared solutions. These are easily made and the color given by a definite quantity of dichromate is readily reproducible.

The above-described method has been used in several varnish specifications with very satisfactory results, and there has been favorable comment from all varnish men who have tried the method. It is not intended that the method should give an optically perfect color match of a varnish, but that it should be a suffciently accurate method of designating the color of a varnish to make it applicable for all practical purposes where the color of a varnish is to be described or fixed. BuREAU OF STANDARDS

WASHINGTON, D. C.

\title{
ADDRESSES
}

\section{PLANNING A RESEARCH LABORATORY FOR AN INDUSTRY ${ }^{1}$}

By C. E. K. MEes

During the last two years the importance and value of industrial research have become widely recognized, and there has been a general awakening on the part of those who control industries to the desirability of including in their organization a research laboratory to act as a nucleus of scientific knowledge for the industry, and to carry out specific investigations which are judged to be of value.

When the executive directing such an industry, however, looks for information as to how to proceed in order to establish a research laboratory, he is likely to find that the specific information which he requires is by no means easy to obtain. While there are many articles pointing out the value of a research laboratory, little has been written as to the steps which should be taken by an industry that has determined to establish one.

Let us take the hypothetical case of the vice president of a company who, as a result of his reading, has become convinced of the desirability of establishing a research laboratory, but who, himself, has no experience in scientific work of any kind, knows only that the greater part of scientific research is done in university laboratories, and has no idea either of the cost of a laboratory, of how it should be established, or of what return he can expect from it. What is he to do in order to present a specific case to his fellow executives, or to proceed in the establishment of a laboratory, should he be empowered to do this?

The object of this paper is to suggest a specific answer to the problem of such an executive, putting the answer in such terms that it may be applicable to a large number of different industries.

In considering the organization of an industrial research laboratory we must deal first with the relation of the research laboratory to the rest of the organization of which it is a part, and, second, with the internal organization of the laboratory itself. The relation of the laboratory to the other departments of the company will be closely associated with the origin of the laboratory.

If there is a technical scientific expert in the executive staff of the manufacturing company, he may have established the laboratory and become its director, and in this case the laboratory will necessarily be very closely associated with the work of the executive who initiated it.

A laboratory may also be established under a separate director, not himself associated with the executive officers of the company, but as a reference department for the executives. In this case also it will be very closely associated with the officers of the company and will tend to be more concerned with questions of policy and the introduction of new products than with any other of the problems of the company.

1 Address delivered April 12, 1918, before the New York Section of the Society of Chemical Industry, the American Electrochemical Society, and the New York Section of the American Chemical Society.
In a large company a research laboratory may be established as a separate department having its own organization, and be available as a reference department for all sections of the company, in which case its activities will cover a very wide field, but at the same time it will not have as direct an influence upon the policy of the company as will happen if it is closely associated with one or more of the executive officers.

Whatever the size of the industrial concern may be, the organization of the research laboratory should be responsible directly to the management.

The work of a research laboratory almost always involves questions of policy, and not merely manufacturing questions, and frequently close connection with the advertising and selling departments of the company is very necessary. In several cases where research work has been conspicuously successful, this has been the case.

Let us assume, therefore, that on the establishment of the research laboratory we are considering, arrangements will be made in the organization of the company by which the laboratory will be brought into contact not only with the manufacturing sections of the company but with the financial and sales direction.

Turning next to the internal organization of an industrial research laboratory, there are two forms of organization possible. For brevity these may be spoken of as the "departmental" system and the "cell" system.

In the departmental system the organization is that familiar to most businesses. The work of the laboratory is classified into several departments: physics, chemistry, engineering, and so on, according to the number necessary to cover the field, and each of these departments has a man of suitable scientific attainments in charge of it. In a large department each of these men will in turn have assistants responsible for sections of the department, all the heads of departments finally being responsible to the director of the laboratory. Under the alternative or cell system the laboratory consists of a number of investigators of approximately equal standing in the laboratory, each of them responsible only to the director, and each of them engaged upon some specific research. Each such investigator, of course, may be provided with assistants as may be necessary.

Each of these systems has advantages and disadvantages. Under the departmental system the advantages are strict organization, good coöperation throughout the departments, a plentiful supply of assistants for the more able men who form the heads of departments or sections of the departments. The chief disadvantage is that the system tends to stifle initiative in the younger men. While it is true that research men require to serve a considerable apprenticeship to older investigators, there comes a time when every man wishes to try to develop his own line of research on his own initiative and to carry out work by himself, and while it is quite possible to provide for such men in a departmental organization, there is some danger that men who are really capable of original work may not get the opportunity to carry it out. The cell system, on the other hand, provides a good arrangement for men of original initiative and 
of the self-reliant type; it enables a man to continue a single line of work by himself for a long time and to bring to a conclusion work which in a departmental organization might have been abandoned because of its apparently unremunerative character. On the other hand, the cell system tends to exaggerate the vices of such men. They tend to become secretive, to refuse coöperation, to be even resentful if their work is inquired into, while if a man who has developed a line of work for himself in a cell leaves the laboratory, it may be difficult for anybody else to take up the work, in which case a great deal of time and money is lost, and work which should have been carried forward is left unfinished. Another objection to the cell system is that men who are good organizers and who are of the type of men that can carry on work requiring many assistants do not easily find a place in it.

In practice, some system between these two systems of organization is essential and will develop in any laboratory. It is not possible to work a rigid departmental system, and, on the other hand, no cell system in its most definite form could be effective. The form of organization which is the easiest in administration is undoubtedly some modification of the departmental system, since only by this means can young students, fresh from college, acquire adequate training and at the same time keep in touch with different branches of their subject and avoid the danger of overspecialization too early. A laboratory should therefore be organized in departments with an intra-departmental arrangement under which a young man who develops the ability to carry out his own work may be able to take up work on his own initiative, still retaining his position in the department and carrying on his work under the general supervision of the chief of his department. There will always be a tendency in the departmental organization for men to desire to split away from the department to which they are attached and become semiindependent in the laboratory, and this tendency must be resisted in the organization and by the director of the laboratory. At the same time, it is important that too rigid a control should not be exercised so that men feel that they are prevented from exercising their own initiative.

A laboratory for a specific industry will generally tend to be of what has been called the "convergent" type, that is, one in which all the different sections of the laboratory representing different branches of scientific work have their energies directed towards the solution of problems relating to the same subject. The problems of such a laboratory will, therefore, all be interrelated and the work of the laboratory will be directed towards one common end.

The organization of such a convergent laboratory has been discussed in a former paper. ${ }^{1}$ It is shown there that charts could be prepared illustrating the organization which would be available for almost any convergent laboratory, so that, if we have to work out the organization of a research laboratory which is to study any interrelated group of problems, we can do it by the construction of similar charts. Thus, we may arrange a chart showing the derivation of the branches of the subject considered from the sections of pure science involved. We can place on one side biological, physical and chemical problems, subdividing each section so that each one represents work capable of being handled by one man in the laboratory. It will now be possible to draw a new chart, showing on the circumference the different sections of the laboratory for which accommodation, apparatus and men must be provided, and showing the relation of these sections to the problem as a whole. Having worked this out, it is easy to find the amount of space and the number of men which will be required, or which the funds available will allow for each part of the work.

Now, before applying these charts for laboratory organization to a specific industry, let us look at the question of the

1 This Journal, 9 (1917), 1137. physical organization of the laboratory itself: the building and scientific equipment, the cost of building, and the cost of the maintenance and operation. It may be mentioned here that when a laboratory is under consideration by the executive of a company, the matters which usually concern his mind are these physical details, and he is often greatly concerned with the planning and cost of the building and equipment, a matter which is quite secondary to the internal organization of the laboratory, either as regards effect on the work or even from a financial point of view.

The laboratory should be housed in a convenient, special building. It is very advisable that all research work under the same general direction should be conducted under the same roof, since only in this way can good coöperation between the departments be obtained, and the facilities and organization of the whole department be available to all the workers. In technical research, where it is often necessary to install model plants on a small scale, this cannot always be carried out, but, as far as possible, a research laboratory should be a real building and not merely the name for a number of scattered departments at some distance from each other.

It is a mistake for a factory to house a research laboratory in some abandoned building designed for other purposes. The annual cost of research work, as will be shown later, is very high in comparison with the cost of the building itself. The greater part of that expenditure is on the salaries of the men carrying out the work, and any inconveniences or disadvantages which may be caused by their working conditions and surroundings can easily depress the production to an extent which renders such economies very unprofitable. The cost of the research man, in fact, is so high that it is worth while to provide him with the very best facilities for carrying out his work, since, provided money is not actually wasted on useless ornaments, these facilities will always be inexpensive in comparison with the total expenditure on the work.

Research laboratories are almost always too small, and it is really desirable that, in designing such a laboratory, some system of construction should be chosen in which expansion can be obtained by the duplication of units. This is, of course, a very difficult thing to arrange, especially in the details of the laboratory, but, nevertheless, it should certainly be aimed at by the architect, since, whatever the size of the laboratory when it is designed, it is safe to prophesy that, within a very few years expansion will be necessary, and if direct expansion is not possible, this will take the form of detached groups of men working in other places, an inconvenient and uneconomical arrangement.

The cost of moving in research work is not always realized. The cost of moving into a new building may be as much as half the total cost of the building, since the men will actually not be working again at full speed in less than six months, and, as a general rule, the annual expenditure is equal to the cost of the building and equipment. It is important, therefore, in designing a laboratory to arrange, if possible, that expansion may take place without any considerable rearrangement. An aid to this is to make the internal divisions of a laboratory movable as far as is possible, and while the laboratory itself should be of fire-proof construction, it will be convenient to make partitions of composition board and wood wherever the fire risk does not prohibit this. In this way, rooms can easily be subdivided, combined or rearranged.

Everything that has been said as to the necessity for the provision of a satisfactory building applies also to the question of equipment, but with even greater force. It is an economic error to allow expensive men to be short of the apparatus which they require for their work. As a general rule, men will not ask for apparatus which they do not need. There are a very few men who might be considered to be apparatus collectors, and who seem to have a real anxiety to surround themselves with all forms of 
scientific apparatus, whether they have any use for them or not; but with the exception of these men, who are limited in number, it may be taken that when a research worker asks for apparatus he needs it, and must have it in some form or other to continue his work.

The total cost of equipment for a physical laboratory represents about two month' cost of operation, and, if economies are to be made, it is clear they should be made in limiting the amount of work undertaken and the consequent cost of operation, rather than in depriving the employed workers of the necessary tools for their work.

From various sources of published information, as well as from personal experience, it is possible to form an estimate of the cost of a research laboratory per scientific worker employed, taking the term "scientific worker" to cover all graduate men working in the laboratory. It might seem that there would be very great variation in the cost, but, provided that we confine ourselves to laboratories of the physical and chemical type, there is a surprising agreement between the different figures, which show that cost of building and equipment for a laboratory will be between $\$ 3000$ and $\$ 4000$ per man; it may be taken, therefore, that the first cost of a laboratory will be about $\$ 3500$ per scientific worker employed. From the same sources the annual cost of maintenance of such a research laboratory appears to be slightly lower than the first cost. Probably $\$ 3300$ per man would be a fair estimate of the cost of maintenance, and of this we may take 60 per cent as representing salaries and wages and the other 40 per cent all other expenses.

Let us attempt to apply the principles which have been laid down to the design of an industrial research la boratory applicable to a specific industry, in such a form that they would be available for the directorate of the industry to understand to what they are committing themselves in establishing a research laboratory, and how to proceed in order to do so.

We may select as an example of a specific industry one of a technical manufacturing type dealing with engineering processes, handling chemicals, 'and also involving certain biological considerations; such an industry, for instance, as textile dyeing or the manufacture of leather goods. Exactly the same principles, however, would apply to industries of quite a different kind. Thus, an industry in which there are no biological considerations will not require some branches of a laboratory; they may need to substitute others in their place. For some industries, physics is of no importance and chemistry is of far more importance.

Let us, however, in order to be specific, consider the question of a plant whose business consists in the dyeing of textiles. Let us suppose that the industry is making a turn-over of $\$ 1,000,000$ a year, of which ro per cent is net profit, and that the directors have decided that, in order to improve their product and extend their business, possibly to diminish costs, they will at the outset undertake an expenditure of $\$ 15,000$ a year on scientific research. Now, let us consider what they can do for this.

In the first place, we can decide at once how many men they can get. On the basis of $\$ 3000$ per man, they should be able to get five men for $\$ 15,000$, but with very few workers in the laboratory, the cost per man will be somewhat higher, and it will be safe to assume that only four men can be obtained for the \$10,000 available for salaries. The cost of the building will be about $\$ 10,000$ and equipment about $\$ 5000$. Taking the basis of $\$ 2.00$ per sq. $\mathrm{ft}$. for building as a rough approximation, we shall have a building with $5000 \mathrm{sq}$. $\mathrm{ft}$. of floot space, or, dividing this into three floors, a building about $40 \mathrm{ft}$. square. The work of the laboratory may be analyzed according to the chart shown herewith. Dividing into the three main divisions of chemistry, physics and biology, we shall get the following sections for the work: In chemistry, we shall require an analyst and dye chemist who must understand organic chemistry, and a colloid chemist who will study the relation between the fiber and the dyes. In physics, we shall have work to do on the testing of the strength of materials and especially on colorimetery and the measurement of absorption. In biology, we shall require a man who understands the vegetable and animal fibers, their structure and their biochemical properties. We shall also require work on the staining of fibers and photomicrography. This will give us the chart shown.

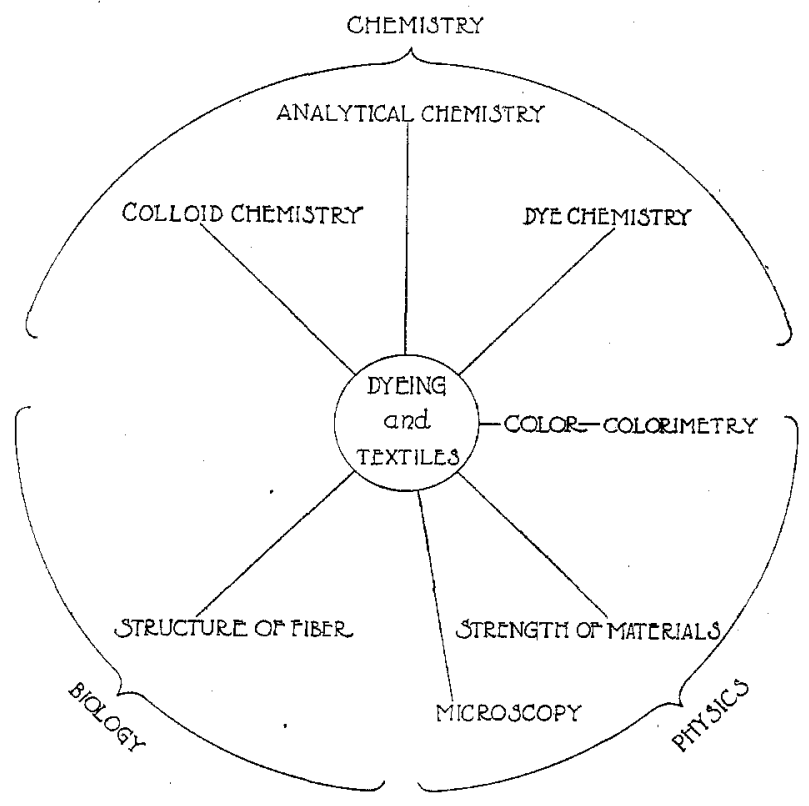

Now, we cannot hope, of course, to represent all these departments by separate men, since we can afford to have only four men, and in addition to the departments shown we must have one practical dyer having actual works experience. Our men may be grouped somewhat as follows: Our organic chemist can look after analytical chemistry as well, that is, we must get a man having experience in organic chemistry and some good knowledge of dyes, who can specialize in the study of dyestuffs and on their analysis, but who also can do what analytical chemistry it becomes essential for the laboratory to carry out. We may expect our colloid chemist to be a biochemist and to take care of the microscopy. The physicist may understand colorimetry and, at the same time, know enough general physics to be able to look after questions involving the strength of materials. We have thus accounted for three of our four skilled men, and the fourth must be the practical dyer, who should also be the director of the laboratory and should have a good training in dye chemistry and general chemistry, with a considerable knowledge of colloid chemistry and fibers, and some knowledge of physics. Thus, the staff of our laboratory will be completed by the director, who will be a chemist who has had works experience in dyeing, and who must be given this works experience before the laboratory is commenced if a fully trained scientific research man is not already available from the works. It is of no use to take a man from the works who is not fully trained in research methods and in sympathy with scientific work, and if such a man is not already available with a knowledge of dyeing, then the best available man must be obtained from a university or elsewhere and given the works experience to learn dyeing before the construction of the laboratory is attempted.

The amount available for the salaries of these men will be about $\$ 10,000$ a year, which must be distributed as seems advisible with regard to the men actually chosen. The sum should be sufficient to obtain fairly good men, as a commencing salary.

We will next consider the structure of the laboratory itself. It must be remembered that we have three floors, each of them containing about $\mathrm{r} 600 \mathrm{sq}$. ft. Of these, one will be required for 
the library, office and the dye room, which will be a small edition of a works department containing small model machines in which all the works processes of dyeing, washing and drying can be carried out. This may occupy about half the ground floor, the other half being taken up by the library, staircase, and the laboratory office, which in such a small laboratory may be united with the library. The next floor will be devoted to chemistry and may be divided into two or three rooms, while the top floor will be used for physics and will contain rooms for ordinary physical work and for colorimetry. It will also probably be used for microscopy, since it is unadvisable to have microscopes and similar instruments exposed to the fumes of a chemical laboratory.

An exactly similar design to this can be made out for any other industry, the factor of size being determined by the expenditure which it is proposed to make, and the work being dissected in accordance with the demands of the particular industry in question. Space must always be kept for a small replica of those plant operations on the investigation of which the laboratory is working, since it will of ten be necessary to prove the plant operations under the direct control of the men in the laboratory and under conditions which can be rigidly maintained at any required point.

Now, let us consider what returns may be expected from the work of this laboratory.

The work of an industrial research laboratory may be classified in three divisions:

A-Work undertaken on the initiative of manufacturing divisions for the improvement of operations, for the lowering of cost, or in order to locate manufacturing difficulties.

$\mathrm{B}$-Work undertaken with a view to the development of new materials or of new processes. This may be initiated by the management, by manufacturing sections, by sales divisions who see the need for such materials or processes, or by the director of the laboratory or his assistants.

C-Work which deals with the fundamental theory of the subject, the results of which, if successful, will lay a foundation for the expansion of the industry as a whole, along lines which usually cannot be foreseen when the research work is commenced.

The work classified under Division $A$ is, of course, common to all industrial laboratories, and many research laboratories in connection with manufacturing plants confine themselves almost entirely to problems arising from the manufacturing division.

Division B includes a large portion of the work of industrial research laboratories and the best known successes of such laboratories are included in this division. A typical example is the development of the drawn wire tungsten filament by the research laboratory of the General Electric Company, a research which, although originating from a general research on the properties of rare metals such as would be classified under Division C, developed into a study of tungsten with the direct purpose of obtaining a satisfactory filament lamp from the metal. Another example is the manufacture of indigo by the Badische Company. Such researches usually have their basis in some more fundamental work; the industrial work on indigo, for instance, was made passible by the original chemical work on the structure of indigo carried out in the German universities, which was applied on a manufacturing scale to the preparation of the dye.

More rarely do research laboratories work on subjects classified under Division $\mathrm{C}$, that is, on the fundamental theory of their subject, yet those who do, achieve the most conspicuous successes. The work of Professor Abbe on the theory of the microscope, and, indeed, all the work on applied optics at Jena comes under this heading. The great success of the Zeiss Works is directly due to the attention paid by Abbé to the development of the fundamental theories of optics. At the General Electric Laboratory at present much attention is being paid to the emission of electrons from hot bodies, and from this work there have already developed the Coolidge $\mathrm{X}$-ray tube and the kenotron high fre- quency transformer, while the possibilities of application are as yet only just beginning to be realized.

In a study of the work of a special research laboratory all the work done during the year was analyzed out from a classification of the work of each part of the laboratory, and the proportionate expense found, which should be charged to each class of the work.

This analysis showed that Division $A$, that is, work done for the manufacturing departments, corresponded to about is per cent of the work of the laboratory; Division $B$, work on new materials, 47 per cent; Division C, or fundamental work, absorbed 27 per cent, of which $22^{1 / 2}$ per cent was devoted to the scientific work and 5 per cent to the accompanying educational work, while work for the assistance and information of the office force is estimated at $5^{1 / 2}$ per cent.

Now, considering this division of the work of the laboratory, it will be agreed that, if proper coördination exists between the laboratory and the management of the company, work classified under $A$ and $B$ will certainly be reasonably remunerative, although not necessarily so completely so as to pay the dividends on an investment in the research laboratory, which are commonly expected from such an investment. The same may not appear true in the case of Division $\mathrm{C}$, the fundamental work, which in the hypothetical case discussed would represent nearly a third of the total expenditure of the laboratory; nevertheless, it is probable that this section of the work would be likely to prove the most remunerative of all, and the way in which this can best be illustrated is by some examples.

Let us consider graded examples of theoretical work in relation to their application in industry.

First, let us take the case of such work as that done by Professor Abbé on the geometrical laws which govern the formation of images by lenses. The connection between this and the manufacture of lenses is so obvious that it is at once manifest that the discovery of any new principle in the theory of lens optics will react immediately upon construction in some way, either in the form of a new product or in cheaper forms of construction.

Next, let us consider work on improved methods of testing such, for instance, as the work done by the various bureaus of standards or research on analytical methods. Here it can be seen that only the possession of an accurate method of testing will enable the manufacturer to improve his product and to guarantee the similarity of product made at different times. Consider, for instance, the improvements in electrical measuring methods and instruments which have made available the standardized electrical equipment which is now so familiar to every one.

In the third place, we may take as an example such research work as the study of the relation between inductance and capacity in alternating electrical circuits, which has had such an immense influence upon the design of alternating current electrical machinery. At the present time, of course, this is a recognized fundamental portion of electrical engineering.

Lastly, let us consider such work as that of the universities on the photoelectric effect, the diffraction of X-rays by crystals, or the emission of electrons by hot bodies. Of these, the last has already found extremely important commercial application, the second one is being adopted by several industrial research laboratories in making a study of the structure of metals, alloys, and other crystalline substances, while the first, so far as I know, up to the present has not found any industrial application, and yet, it may safely be prophesied, will be of importance to industry within the next ten years.

It is almost impossible to name any class of physical or chemical scientific work, from the physics of the atom to structural organic chemistry, which will not sooner or later have a direct application and importance for the industries.

Work in a research laboratory bears a certain analogy to placer mining for gold. A man washing gold can make a living by steady, hard work, but nobody would take up placer mining 
with the intention of making a living by the every-day washing. Everybody hopes to find nuggets which will give them a good profit, and possibly even a fortune. In the same way a research laboratory can produce results equivalent to a large amount of its expenditure by steady work, but from a commercial point of view research is undertaken in the hope of the occasional valuable discovery rather than for the steady output of small details.

The analogy can be carried somewhat further. Just as in placer mining it is of no use looking for nuggets, and any miner who neglects the routine washing in search of nuggets is likely to starve before he finds them, in the same way a research laboratory cannot look for discoveries. It can only carry on its every-day work on the problems presented to it, and hope that when some possibility of a valuable discovery presents itself it may recognize it in time to take advantage of the fact.

There is, however, one direction in which this analogy breaks down. When a man finds a nugget, he knows its value and its value is definite and certain; in research work this is not the case. Discoveries which are thought to be valuable when made often prove worthless, while others which appear to be of no value eventually turn out to be profitable, and frequently the value of a discovery is not under control of the laboratory because the adoption and exploitation of it may be in other hands.

It is sometimes thought that in order to put an industry into a state of complete efficiency from a scientific point of view all that is necessary is to establish a laboratory and to employ a scientific staff to carry out research work. It is quite possible, however, for such a laboratory to have no influence whatever upon the general policy of the company, and only a very slight influence upon its manufactures, the value of a laboratory depending very greatly upon the closeness of its coöperation with the other departments of the company.

It is often felt that small industries cannot afford to support scientific research, but this argument is exactly as if it were suggested that small industries cannot afford to support advertising. The object of spending money on research, for a small industry at any rate, is not to support the research but to be supported by it, and it is scarcely an exaggeration to say that the smaller a business is, the more important is it that it should make use of scientific research to the greatest extent possible.

A small business is at a disadvantage in comparison with a large one in regard to all its cost charges. In the purchase of raw materials, in manufacturing, and in selling, its cost per unit of output tends to be larger than in the case of big businesses, but, on the other hand, it is at a real advantage in regard to flexibility and enterpírise. Any large business must necessarily be cautious and conservative. The amount at stake is so large that the penalty of error is heavy. Consider, for instance, the mere cost of allotting half a page in a catalogue of which three million copies are to be printed. It is clear that no business man will allow the introduction of a new article into a catalogue for which such an edition is necessary unless he has reason to believe that the demand will be sufficient to pay the cost involved. That is, the machinery of a large business is adapted for the sale of things for which there is a large demand, but it is difficult for it to introduce articles for which the demand will probably be limited and doubtful. Every large business is anxious to improve its goods, since it knows perfectly well that the penalty for failure to do this is extinction, but it necessarily moves with greater caution and more slowly than a small business can do. It is this very fact, rightly grasped, which enables the small business to get its start and grow in spite of the advantage in regard to cost possessed by its larger competitor, and the growth of a small business will depend upon its supply of ideas for new products and new methods to a far greater extent than will that of the big manufacturing concern making staple products. Small businesses can, therefore, make far more use of a research laboratory and get a much bigger percentage return for the expenditure than any big company can hope to do. In the small business, in fact, a research laboratory closely associated with one of the high executive officers should begin to return a profit within a few months of its establishment, whereas in the case of a large company it may be years before a research laboratory can be considered to be financially successful.

The greatest difficulty in the establishment of a research laboratory in a small business is that any research laboratory will depend for its value upon the quality of the men at the head, or, if the laboratory is really small, of the man at the head, and a small business often feels that it cannot afford to pay even one good scientific man. The solution of this in a technical business might be that the research man should also be an officer of the company, so that his cost is borne not only by the scientific work but also by the value of the executive position which he holds.

It may be objected that an investigator would not as a rule prove a capable business man, but there really seems to be no particular evidence for this common belief, and there are many examples of men trained in science who have proved extremely good administrators. The classic example is, of course, the organization of the great Zeiss works under Professor Abbé, but in many cases it will be found that the technical industries are directed by technical men who were themselves directly concerned with development and manufacture rather than with financial or business direction.

When the question with which this paper starts was put to a chemist much experienced in research work, and he was asked what he would say to an executive who requested information as to how to proceed to establish a research laboratory, he answered without hesitation that he would tell him to search until he found a suitable man to be director of it, and then leave it to the man to establish the laboratory. There is no doubt very much truth in this view, and the success of a laboratory must stand or fall in great measure by the quality of the man in charge of it. But it is often desirable for business men to come to some conclusion about research when they have in mind no man suitable to undertake the formation of a laboratory for them, and it is in the hope of aiding technical or business executives in such a position that the present paper has been written.

EASTMAN KODAE COMPANY

ROCHESTER, NEW YORK

\section{THE AMMONIA PROGRAM FOR I9I81}

By Charlas W. MERrilL

\section{PREIIMINARY CONGIDERATIONS}

I do not need to tell you that ammonia produced in America prior to the war was all consumed in essential industries such as refrigeration, domestic explosives, dry batteries, fertilizers, and so forth. You also know that there were large imports before the war, which, it was realized, would be cut off, and that, furthermore, there would probably be enormous demands for military explosives. These two factors indicated that it might be necessary, not only to provide new sources of supply and to economize in present uses, but also possibly to drastically curtail present uses.

The War Department, fortunately, appreciated this and planned and prepared for new plants: one a cyanamide fixation plant; and another a plant for the conversion of sulfate to nitrate, these both in addition to the small Haber plantalready authorized. Both of these larger plants are reported to be well under way. They are expected to begin production on a very material scale not later than this Fall. Private enterprise has also been active in an endeavor to meet the increased demands. New byproduct coke ovens are being installed, and an aluminum nitride

I Address before the Washington Section of the American Chemical Society, April 11, 1918 